\title{
Profiles of institutional ethics committees and status of standard operating procedures in North East India
}

\author{
BISHNU RAM DAS, GITALI KAKOTI
}

\begin{abstract}
Limited data are available regarding institutional ethics committees (IECS) and their standard operating procedures (SOPs) in North East (NE) India. An attempt was made to study the profiles of IECS and the status of their SOPs in health research institutes of NE India. Fourteen biomedical and health research institutes of NE India were reviewed. Only 12 of these 14 institutes had constituted their IECs. The IECs were multidisciplinary and multisectoral in nature; of the 12 institutes, 8 had adequate representation by age and seven committees had adequate representation by gender. In 11 out of 12 IECS, chairpersons were non-affiliated, and chairperson qualifications in 10 of 12 IECS were found to be in keeping with the National Ethical Guidelines for Biomedical and Health Research involving Human Participants, 2017, of the Indian Council of Medical Research (ICMR). There were no lay persons in 6 out of 12 IECs. Nine out of 12 institutes had framed their SOPs. Three out of nine IECS adopted all three types of reviews namely exemption from review, expedited review and full committee review. Six out of nine SOPs had adopted the provision of quarterly review meetings. Declarations of conflict of interest (Col) were specified in seven out of nine SOPs. Five out of nine SOPs mentioned no voting power for members who declared Col. Seven out of nine SOPs specified the designated office space, staff, and budget of the committee. Only 2 out of the 12 IECs were registered. Our findings concluded that the characteristics and composition of IECs of health research institutes in NE India are suboptimal. Most of the SOPs were not framed as per recommendations of the ICMR National Ethical Guidelines for Biomedical and Health Research Involving Human Participants, 2017, and were unregistered.
\end{abstract}

Keywords: Institutional ethics committee, standard operating procedure, North East India

\footnotetext{
Authors: Bishnu Ram Das (drbishnu07@yahoo.co.in), Professor and Head, Department of Community Medicine, Jorhat Medical College, Jorhat 785 001, Assam, INDIA; Gitali Kakoti (kgitali@yahoo.in), Woman Scientist ,DHR, Department of Community Medicine, Jorhat Medical College, Jorhat 785 001, Assam, INDIA.

To cite: Das R B, Kakoti G. Profiles of institutional ethics committees and status of standard operating procedures in North East India. Indian J Med Ethics. 2021 Apr-Jun; 6(2) NS: 156-162. DOI: 10.20529/IJME.2020.124.

Published online first on December 6, 2020.

Manuscript editor: Vijayaprasad Gopichandran

Peer Reviewers:Two anonymous peer reviewers

(c) Indian Journal of Medical Ethics 2020
}

\section{Introduction}

The rapid growth of biomedical and health research in the current globalised era has added new responsibilities for researchers, institutes conducting research, and ethics committees. In this context, an appropriately constituted functional institutional ethics committee (IEC) has a significant role in the protection of the dignity, rights, safety, and wellbeing of research participants. Each biomedical and health research Institute (BHRI), where research involving human participants is being conducted, is accountable for constituting an independent IEC and should have a written standard operating procedure (SOP) according to which the committee should function (1). All BHRIs are required to refer to the National Ethical Guidelines for Biomedical and Health Research Involving Human Participants, 2017, of the Indian Council of Medical Research (ICMR) (henceforth ICMR 2017 guidelines) in constituting their IECS and framing SOPs to review all research protocols involving human participants and the Drugs and Cosmetics Rules, 1945, of the Government of India (hereinafter referred to as GOI, DC rules1945) for drug and device trials in India (1: p 25, 2).

In recent years, there has been public resentment about the exploitation of potentially vulnerable research participants by breach of the conditions of responsible research. The unethical behaviour of agencies conducting research can damage public trust in research and the researcher (1: p13). India has seen several documented cases of ethics dumping in research on marginalised, weak, and vulnerable research participants (3).

The licensing authorities have not made it mandatory to take regulatory permission in case of non-drug trials (2: $p$ 146). Even regulatory bodies like the Medical Council of India (MCl) and Central Drugs Standard Control Organisation (CDSCO) have little or no control over IECs in academic medical institutes for non-regulatory research. Lately, following a verdict of the Supreme Court of India, the Ministry of Health and Family Welfare, Government of India (MoHFW, GOI) has directed all the IECs of institutions involved in regulatory research to register with the CDSCO (2:p 146).

In recent times, $\mathrm{MCl}$ has made it compulsory to include peerreview of research publications as one of the criteria for career advancement in medical colleges in India (4). However, no criteria have been specified to maintain standards of ethical review and monitoring. All this has compromised the fundamental values of research (5).

Researchers and ethics committee members ought to be aware of and comply with the scientific, medical, ethical, legal, and social requirements of the research proposal (1:p 5). The 
successful protection of research participants depends mostly on the existence of appropriately constituted functioning IECs and their independence in dealing with ethics applications (1: p 25).

In India, institutional mechanisms for ethical review of research involving human participants are weak and vulnerable (5). In spite of having National Ethical Guidelines, more than $50 \%$ of the research institutes in India, reportedly, lack official IECs and are still struggling with basic issues like lack of trained manpower, lack of space, poor administrative support, heavy work load, unsatisfactory or no SOPs, and nonconformity with Schedule $Y$ recommendations $(6,7,8,9)$ for trials conducted under the Drugs and Cosmetics Act.

In an ICMR study, Kumar NK stated that limited researches have been conducted in the past in the field of biomedical and health sciences in North Eastern India (NE India) because of law and order issues evolved following insurgency movements. There were also fewer awareness/training programmes on bioethics (7).

To improve the standard of research and its review by IECs, it is necessary to build capacity in bioethics and ethics committee administration among IEC members and young researchers of medical colleges and biomedical and health research institutes in NE India. Thus, it was decided to conduct a study to understand the current status of IECs and the SOPs of biomedical and health research institutes located in this region.

\section{Objective}

To assess the composition of IECs and status of SOPs of IECs in biomedical and health research institutes of NE India

\section{Methods}

\section{Study design}

A cross-sectional institution-based observational study was conducted over a period of six months in 2018. In this study, we enlisted all the $\mathrm{MCl}$-recognised medical colleges in the $\mathrm{NE}$ region of India and biomedical research organisations and/or referral hospitals in the public sector in Assam. where biomedical research is being conducted. There were only twelve $\mathrm{MCl}$-recognised medical colleges in the NE region at the time of our study.

We enrolled 14 biomedical and health research institutes which had given their consent to participation in this study and from which we could obtain the latest IEC notification and/or SOPs. Among them,12 were $\mathrm{MCl}$-recognised medical colleges in the NE states, namely, Assam, Manipur, Meghalaya, Tripura, and Sikkim and conveniently incorporated one health research institute of ICMR under the Ministry of Health and Family Welfare (MoHFW), Government of India (Gol) and an Air Force Hospital under the Aviation Ministry of Gol located in Assam. There were no $\mathrm{MCl}$-recognised medical colleges in Nagaland and Mizoram during our study period.

\section{Data collection procedure}

We approached the administrative heads of all these institutes to obtain administrative clearance to incorporate their IECs and SOPs in the present study. All possible efforts were made to collect the notification of IECs and SOPs through email from the institutional head or Member Secretary, or through faculty members working in the respective institutes. An effort was also made to download the notifications of IECs and SOPs from the respective institute's website, if they were available in the public domain.

A pre-designed and pretested questionnaire was used to collect data in line with the ICMR 2017 guidelines (1). Study materials used were the latest notifications of IECs for human participants and up to date versions of SOPs of the IECs of the respective medical colleges, research institutes, and referral hospitals. The information collected related to the characteristics and composition of the IECs, affiliation and qualifications of IEC members, review and record keeping procedures, and financial and material status. To simplify the study and to minimise errors, we specified the inclusion criteria, namely, the Institutional Ethics Committees Human $\mathrm{H}$ ) willing to provide the latest IEC notification and/or SOP of IEC $(H)$ or to give permission to download the said materials if available on their institute website for public use. We excluded those IECs of medical colleges which were not recognised by the $\mathrm{MCl}$ or were in the process of obtaining the letter of permission at the time of our study.

\section{Data analysis}

Desk evaluation of the collected IEC notifications and SOPs was done. During the discussion, tabulated results were compared with the ICMR 2017 guidelines, which were taken as the gold standard (1). Strict confidentiality was maintained while handling the dataset and institute names were delinked. Data were processed and analysed using Statistical Software and MS Excel 2010, and documented using MS Word 2010.

\section{Ethics clearance}

Due permission was obtained from the IEC $(\mathrm{H})$, Jorhat Medical College and Hospital, Jorhat, Assam.

\section{Results}

\section{State wise status of IECs and SOPs}

Of the 14 BHRIs of the NE Region, only 12 had constituted their IECs and this was officially notified. Except Assam, all the NE health research institutes (all four) had their IECs in place, while in Assam only six of the eight health research institutes had constituted their IECs.

With regard to SOPs, it was found that only nine of 12 IECs in the NE region had framed their SOPs. State-wise availability of SOPs confirmed that, in Assam, four of the eight and in Tripura one of the two institutes had structured their SOPs; while, both institutes in Manipur, one in Meghalaya, and one in Sikkim had adequate numbers of SOPs in all their IECs.

Displaying of SOPs on the respective institutional websites revealed that six of the eight institutions of the NE states have displayed their SOPs in the public domain. Among them an incomplete display was seen in two out of the four institutes in Assam and one out of two in Manipur.

\section{Characteristics and composition of IECs and IEC members}

We found that all the 12 IECs were multidisciplinary and multisectoral in nature. There was adequate age representation in eight and gender representation in seven of 
Table 1: Characteristics and composition of IEC according to ICMR 2017 guidelines $(n=12 *)$

\begin{tabular}{|l|l|l|}
\hline Characteristics & Numbers & Percentage \\
\hline Multi-disciplinary & 12 & 100 \\
\hline Multi-sectoral & 12 & 100 \\
\hline Adequate age representation & 8 & 66.7 \\
\hline Adequate gender representation & 7 & 58.3 \\
\hline Non-affiliated IEC members & \multicolumn{2}{|l|}{} \\
\hline $\begin{array}{l}\text { Number of committees having non- } \\
\text { affiliated members } \\
>50 \%\end{array}$ & 4 & 33.3 \\
$<50 \%$ & 8 & 66.7 \\
\hline $\begin{array}{l}\text { Numbers of IEC members between } 7 \\
\text { to 15 }\end{array}$ & 12 & 100 \\
\hline $\begin{array}{l}\text { Balance between medical and non- } \\
\text { medical/technical and non-technical } \\
\text { members }\end{array}$ & 6 & 50 \\
\hline $\begin{array}{l}\text { Chairperson } \\
\text { Non-affiliated chairperson }\end{array}$ & 11 & 91.7 \\
\hline $\begin{array}{l}\text { Affiliated } \\
\text { No IEC constituted }\end{array}$ & 2 & \\
\hline
\end{tabular}

the IECs (Table1). The number of IEC members ranged between 7 and 15 in all the IECs. Only in six IECs was there a balance between medical and non-medical/technical and non-technical members.

With regard to non-affiliation of chairpersons, it was found that 11 of the 12 IECs had non-affiliated chairpersons, while 10 of the 12 chairpersons had qualifications that met the requirements of the ICMR 2017 guidelines. Eight of the twelve IECs had less than $50 \%$ non-affiliated members. All the member secretaries were found to be affiliated to the host institutes, and their qualifications were according to ICMR standards. In 11 of the 12 IECs, basic medical scientists and clinicians were affiliated to the host institute, and their qualifications were according to the ICMR 2017 guidelines.

Affiliation of the legal experts showed that, in eleven IECs, legal experts were non-affiliated (ie from outside the host institute). The qualifications of the legal experts in all the IECs were as mentioned in the ICMR guidelines.

Social scientists, philosophers, ethicists and theologians were found in 10 of the 12 IECs. Of these, nine were non-affiliated. The qualifications of these members were not mentioned in any of the IEC notifications or SOPs.

Lay persons were found only in six of the available twelve ethics committees, and they were non-affiliated members. Of these, the qualifications of three lay members were not mentioned.

We enquired about whether there was any written statement in the SOPs regarding quorum requirements during IEC meetings as specified in ICMR 2017 guidelines and found that seven of the nine had specifically mentioned the requirement of a quorum in the respective SOPs.

It has been observed that, in eleven of the twelve IECs, the members were appointed by the head of the host institute, while in one, the appointment was issued by the Under
Secretary to the Government.

In five of the nine IECs the term of the committee was mentioned as $2-3$ years. The tenure of the IEC was not stated in one SOP.

Provision of honorarium to IEC members for attending meetings were made only in five of the nine IECs. Two of the SOPs did not mention any provision of honorarium.

Provision for the training of IEC members was specified in five SOPs. Four SOPs did not mention anything about the training. Roles and responsibilities of IEC members were defined in eight of the twelve SOPs (Table 2).

\section{Submission and review procedure}

It was observed that only five out of the nine SOPs had mentioned the check list and content of documents to be attached by the researcher while submitting a research proposal (Table 3).

With regard to the type of review procedure of the IECs, it was found that three of the nine IECs adopted all the three types of reviews, namely full review, expedited review, and exemption from review. To our surprise, one SOP contained no mention of the type of review to be adopted, while another five SOPs mentioned only two types of review (full and expedited).

\section{Frequency of meetings}

It was revealed that six of the nine SOPs had mentioned that the ethics committee will meet four times a year to review research proposals. However, in three SOPs frequency was not mentioned.

\section{Conflict of interest, voting power, and decision making}

In seven of the nine SOPs, there was clear indication that members will declare any conflict of interest (COI) before the chairmen of their respective IECs in writing. However, only in five SOPs, it was stated that there would be no voting power for members who had declared COI. It was revealed that seven of nine IECs adopted consensus of the board as the decision-making method, while in one, decision-making was to be based on majority votes.

\section{Record keeping and archiving}

It has been observed that eight out of nine SOPs had clauses about record keeping and record archiving. There was no uniformity of record keeping, with duration ranging from a minimum of 5 years to a maximum 15 years.

\section{Administration and budget}

With regard to IECs office administration, it was found that seven out of the nine SOPs had indicated provision of designated office space, staff, and budget to run the IEC activities

\section{Registration and accreditation of IECS}

It was interesting to note that only two of the 12 IECs of the $\mathrm{NE}$ region were registered with the appropriate authority and due accreditation had been given. However, only one IEC had renewed this registration in the entire region. 
Table 2: Affiliation, qualification of IEC members ( $n=12)$

\begin{tabular}{|c|c|c|c|}
\hline \multirow[t]{3}{*}{1} & \multicolumn{3}{|l|}{ Chairperson } \\
\hline & - Non-affiliated Chairperson & $11(91.7)$ & $1(8.3)$ \\
\hline & $\begin{array}{l}\text { Qualifications of } \\
\text { Chairperson as per ICMR } \\
\text { Guideline } 2017\end{array}$ & $10(83.3 \%)$ & $2(16.7)$ \\
\hline \multirow[t]{3}{*}{2} & \multicolumn{3}{|l|}{ Member Secretary } \\
\hline & - Affiliated & $12(100)$ & 0 \\
\hline & $\begin{array}{l}\text { Qualifications as per ICMR } \\
\text { Guideline } 2017\end{array}$ & $12(100)$ & 0 \\
\hline \multirow[t]{3}{*}{3} & \multicolumn{3}{|l|}{ Basic Medical Scientist } \\
\hline & - Affiliated & 11(91.7) & $1(8.3)$ \\
\hline & $\begin{array}{l}\text { Qualifications as per ICMR } \\
\text { Guideline }\end{array}$ & $12(100)$ & 0 \\
\hline \multirow[t]{3}{*}{4} & \multicolumn{3}{|l|}{ Clinician } \\
\hline & - Affiliated & $11(91.7)$ & $1(8.3)$ \\
\hline & $\begin{array}{l}\text { Qualifications as per ICMR } \\
2017 \text { guidelines }\end{array}$ & $12(100)$ & 0 \\
\hline \multirow[t]{3}{*}{5} & \multicolumn{3}{|l|}{ Legal Expert/s } \\
\hline & - Affiliated & $1(8.3)$ & $11(91.7)$ \\
\hline & $\begin{array}{l}\text { Qualifications as per ICMR } \\
\text { 2017guidelines }\end{array}$ & $12(100)$ & 0 \\
\hline \multirow[t]{4}{*}{6} & \multicolumn{3}{|c|}{ Social Scientist/Philosopher/Ethicist/Theologan } \\
\hline & - Affiliated & $1(10)$ & $9(90)$ \\
\hline & - Not present & $2(16.6)$ & \\
\hline & $\begin{array}{l}\text { Qualifications as per ICMR } \\
2017 \text { guidelines stated }\end{array}$ & 0 & $12(100)$ \\
\hline \multirow[t]{5}{*}{7} & Lay person(s) & & \\
\hline & Status & Numbers & Percentage \\
\hline & - Non-affiliated & 6 & 50 \\
\hline & - No Layperson & 6 & 50 \\
\hline & $\begin{array}{l}\text { Qualifications as per ICMR } \\
2017 \text { guidelines }\end{array}$ & 3 & 50 \\
\hline \multirow[t]{2}{*}{8} & \multicolumn{3}{|c|}{$\begin{array}{l}\text { Quorum requirements specified in SOPs as per ICMR } 2017 \\
\text { guidelines }\left(n=9^{*}\right)\end{array}$} \\
\hline & - Yes & 7 & 77.8 \\
\hline \multirow[t]{9}{*}{9} & \multicolumn{3}{|c|}{ Terms of references for IEC members } \\
\hline & \multicolumn{3}{|c|}{ Selection/appointment process to committees $(n=12)$} \\
\hline & $\begin{array}{l}\text { - Appointed by Head of the } \\
\text { institute }\end{array}$ & 1 & 91.7 \\
\hline & \begin{tabular}{|l|}
$\cdot$ Others \\
\end{tabular} & 1 & 8.3 \\
\hline & \multicolumn{3}{|l|}{ Term of IEC membership $\left(n=9^{*}\right)$} \\
\hline & $\begin{array}{l}\text { Tenure of IEC membership } \\
\cdot<2 \text { years }\end{array}$ & 1 & 11.1 \\
\hline & $\cdot 2-3$ years & 5 & 55.6 \\
\hline & $\cdot>3$ years & 2 & 22.2 \\
\hline & - Not mentioned in SOP & 1 & 11.1 \\
\hline
\end{tabular}

\begin{tabular}{|c|c|c|c|}
\hline \multirow[t]{5}{*}{10} & \multicolumn{3}{|l|}{ Honorarium (n=9*) } \\
\hline & $\begin{array}{l}\text { Provision of Honorarium to } \\
\text { IEC members for attending } \\
\text { meeting }\end{array}$ & Numbers & Percentage \\
\hline & - Yes & 5 & 55.6 \\
\hline & $\begin{array}{l}\cdot \text { No provision of } \\
\text { honorarium }\end{array}$ & 2 & 22.2 \\
\hline & - Not mentioned in SOP & 2 & 22.2 \\
\hline \multirow[t]{4}{*}{11} & \multicolumn{3}{|l|}{ Training $(\mathbf{n}=9 *)$} \\
\hline & \multicolumn{3}{|l|}{$\begin{array}{l}\text { Provision for Training of IEC } \\
\text { members specified in SOP }\end{array}$} \\
\hline & - Yes & 5 & 55.6 \\
\hline & - Not mentioned in SOP & 4 & 44.4 \\
\hline \multirow[t]{4}{*}{12} & \multicolumn{3}{|c|}{ Roles and responsibilities $(n=9 *)$} \\
\hline & $\begin{array}{l}\text { Roles and responsibilities of } \\
\text { IEC members defined in SOP }\end{array}$ & & \\
\hline & - Yes & 8 & 88.9 \\
\hline & - No & 1 & 11.1 \\
\hline & & & \\
\hline
\end{tabular}

\section{Discussion}

\section{State-wise status of IECs and SOPs}

An attempt was made to study the composition of IECs and prevailing status of the SOPs of IECs in health research institutes of NE India.

We recorded that a majority of the health research institutes in NE India had constituted their IECs for biomedical research involving human participants and due notification was issued. Assam occupied the lowest position where $75 \%$ health research institutes had constituted their IECs. Similar findings had also been observed in studies conducted earlier $(6,10$, $11)$, where it was noticed that, in spite of having guidelines, many research institutes reported non-existence of their own IEC or affiliation to any nearby institute. The non-existence of IECs in health research institutes in Assam was mostly due to lack of trained manpower, lack of knowledge, lack of interest/ attention among the administrative heads, and lack of a legal framework to constitute the IEC till the time of our study.

With regard to SOPs, it was found that, in the NE region only $75 \%$ of the IECs of health research institutes had framed their SOPs. In contrast, a study conducted by Sleem et al (12) in Egypt reported that almost $83.3 \%$ of the surveyed research ethics committees had SOPs. In Assam and Tripura, half of the IECs did not develop their SOPs. An earlier study in subSaharan African countries also made a similar observation (13). Without a written SOP, the IECs may pursue different methods of submission, approval, and follow up of research (5). This eventually may result in weak ethical review and monitoring. Hence, IECs may be unsuccessful in protecting the dignity, rights, safety, and well-being of research participants.

Displaying of SOPs and IECs notification on the websites of the institutes was not uniform. Overall in the NE region, it was 
Table 3: Submission and review procedure ( $n=9 *)$

\begin{tabular}{|c|c|c|c|}
\hline SI.No & $\begin{array}{l}\text { Characteristics as per ICMR } \\
2017 \text { guidelines }\end{array}$ & Frequency & $\begin{array}{l}\text { Percentage } \\
\text { (\%) }\end{array}$ \\
\hline \multirow[t]{3}{*}{1} & $\begin{array}{l}\text { Check list of documents to } \\
\text { be submitted for IEC review }\end{array}$ & & \\
\hline & - Check list present & 5 & 55.6 \\
\hline & - Check list absent & 4 & 44.4 \\
\hline \multirow[t]{3}{*}{2} & $\begin{array}{l}\text { Mention about details of } \\
\text { documents to be included } \\
\text { in the protocol }\end{array}$ & Frequency & Percentage \\
\hline & - Yes & 7 & 77.8 \\
\hline & $\cdot$ No & 2 & 22.2 \\
\hline \multirow[t]{5}{*}{3} & Types of review & Yes & Percentage \\
\hline & - All three types & 3 & 33.3 \\
\hline & - Only two types & 5 & 55.6 \\
\hline & - None mentioned & 1 & 11.1 \\
\hline & \begin{tabular}{|l|} 
Total \\
\end{tabular} & 14 & 100 \\
\hline
\end{tabular}

Excludes those which did not constitute IECs and had no SOPS

low, and the picture was worse in Assam and Tripura.

Notification of an IEC and SOP is a non-confidential document and is required to be made publicly available (on websites) (14). However, it is yet to be implemented in letter and spirit in many of the health research institutes in the NE region.

\section{Characteristics and compositions of IECs and IEC members}

We evaluated the characteristics and compositions of the IECs among the available 12 IECs and found that all the IECs were multidisciplinary and multisectoral in nature as laid down in the ICMR 2017 guidelines (1: p 28). Conversely, age and gender representation were not up to the mark in many of the IECs. In a study conducted in South Africa earlier, in $83 \%$ of health research ethics committees, less than half of the members were female (15). In this study, the sizes of the notified IECs ranged between 7 and 15. The balance between medical and non-medical/technical and non-technical members was not maintained in half of the IECs. According to a study conducted in Thailand, the average number of committee members was 14 , and the majority were scientific members (16). Similarly, Saito T (17) reported inappropriate composition in a majority of ethics committees in Japanese medical schools, and recommended that more members from outside of the institute, younger members, and female reviewers be added to the committee. Our findings indicate that either the health research institutes in the NE region were not aware of the requirements for composition of IEC laid down in the recent ICMR 2017 guidelines (1: p 28), or were poorly motivated to abide by the norms specified in the said guideline. However, most Indian medical schools do not offer any recognised bioethics training in graduate and postgraduate courses, and it is apparently difficult to get external members trained in bioethics. There is more demand for professionals trained in bioethics in India $(5,18)$.
It is imperative to note that, in a majority of the IECs, the Chairpersons were appointed from outside the host institutes, and their qualifications were in accordance with the ICMR 2017 guidelines(1: p 28). Contrary to our observations, a previous study conducted in public sector teaching hospitals in Delhi by Singh S in 2009 (10) found that only $71.4 \%$ IEC Chairpersons were affiliated to the host institutes. According to the ICMR 2017 guidelines, non-affiliated EC members should be $50 \%$ in ethics committees. However, we recorded less than $50 \%$ non-affiliated members in 8 of the 12 IECs. In our study, all member secretaries and most basic medical scientists and clinicians were affiliated to host institutes. The legal experts of the IECs were generally not affiliated to the host institutes. The qualifications of the member secretaries, basic medical scientists, clinicians, and legal experts were found to be as per rules. It is noteworthy to mention that, while constituting the IECS of health research institutes in the NE region, the ICMR 2017 guidelines were consulted. In a majority of IECs (10 out of 12), social scientists, philosophers, and theologians were present, and in most cases, they were not affiliated to the host institutes. However, their qualifications were not disclosed in the IECs notifications or SOPs. Appropriate constitution of IECs following national guidelines was also observed in an earlier study (19). However, a study conducted by ICMR in 2000 observed that there was no legal expert in most of the IECs, and appointment procedures were questionable (7). It was noted that half of the IECs did not have any lay person. Earlier, Nair and Martin had stated that "lay persons" can be intimidated by the presence of more powerful scientific members (5). Representation of lay persons in IECs was observed as a significant weakness (19). Lack of a lay person in IECs may be because of low importance given to them or because lay persons are not viewed as essential members of the IECs as per Schedule $Y$ notification (8).

Quorum formation is one of the essential requirements of IEC meetings. It has been observed that the quorum requirement was not mentioned in two of the SOPs. This clearly shows that these institutes have considered the necessity of a quorum formation inadequately. The ICMR 2017 guidelines state that, in each ethics committee meeting, a minimum of five members should be present for quorum formation, and the quorum should include both medical, non-medical or technical, or/and non-technical members. Further, at least one non-affiliated member should be part of the quorum and preferably the lay person (1: p 30, 7, 18). Therefore, the validity of ethics committee meetings which are held without a quorum is questionable.

Almost all the IECs members, other than one where the appointing authority was the undersecretary to the state government, were appointed by the heads of the institutes. The head of the institute should act as an appellate authority to appoint the committee members or to handle any disputes if arises (1:p 31).

It was observed that the tenure of IECs varied from 2 years to 3 years. In general, the term of IEC membership may be 2 to 3 years. The duration could be extended as set out in the SOPs. It is a good to practice to have a defined percentage of IEC members changed at regular intervals; this will give more people opportunities to participate $(1: p 31,8,19)$.

Provision of honorarium to IEC members was made in more than half of the IECs. This finding is consistent with the findings of previous studies $(9,10,12)$. The ICMR 2017 guidelines advocate that IEC members may be given a reasonable 
honorarium for attending the IEC meetings (1: p31). It will keep IEC members motivated and make them accountable to attend meetings.

We observed that a provision for training was specified only in five of the nine SOPs. The poor training provisions were also found in several previous studies $(9,10,14,18,19)$. All IEC members should undergo initial and continuing training with regard to research participants' protection, IEC functions, and SOPs. They should be thoroughly conversant with ethical guidelines, GCP guidelines (where applicable), and the relevant regulations of the country $(1: \mathrm{p} 32-33,7,9,18)$. Our study revealed that there is an urgent need for training of IEC members in the NE region of India.

Regarding roles and responsibilities of IEC members, we found that they were mentioned in the majority of SOPs. ICMR 2017 guidelines state that responsibilities of members should be clearly defined in the SOPs, and it should be provided to IEC members at the time of their appointment (1: $p$ 25).

\section{Submission and review procedure}

Evaluation of details of the documents to be submitted to the IECs along with the research proposal for ethical review revealed that many of the IECs did not create any checklist to be used by the principal investigators. However, the checklists of those IECs that had framed them were in line with the ICMR 2017 guidelines (1: p 34).

Types of reviews varied from IEC to IEC, and in three of the SOPs, it was mentioned that all the three types of reviews will be adopted. However, there was no mention of who would decide on the type of review to be carried out, and on what basis the type of review would be decided. The ICMR 2017 guidelines clearly state that "The Member Secretary/ Secretariat shall screen the proposals for their completeness, and depending on the risk involved, categorize the research protocol into three types, namely, exemption from review, expedited review, and full committee review"(1: p 37). Strengthening of existing ethical review procedures is of paramount importance for laying a good foundation for ethical research (19).

\section{Frequency of meetings}

Regarding the frequency of meetings, six of the nine SOPs specified that the full committee will meet quarterly. However, in some SOPs, frequency of full committee meetings was not stated. A study conducted earlier revealed that the number of meetings ranged from 2 to 6 in a year or as per need (10). Thatte and Bavdekar include infrequent meetings as one of the major ethical concerns (18). Unnecessary delay of the approval/rejection of the research proposal may lead to withdrawal of research funding by the sponsor as well as reduce the probability of getting funding in future from the same sponsors, and may increase the cost of research (11). Ideally, IECs should meet regularly, adopt best practices, try to reduce turnaround time, and have procedures in place for early decision-making so that research is not delayed (1: $p$ 38).

\section{Conflict of interest, voting power, and decision- making}

It is obligatory to declare or disclose potential COI by the researcher as well as the members. If a member has declared a COI, then that should be submitted in writing to the chairperson before the start of the meeting, and it should be mentioned in the minutes of the meeting. Members with $\mathrm{COI}$ should not take part in the decision-making process, and should preferably leave the room during the decision-making on the particular proposal with reference to which $\mathrm{COI}$ was submitted (1: p 41). The ability of an impartial review is compromised in the presence of members with conflicting interests $(10,19)$. In our study, we found that there was a clear statement in the majority of SOPs that the COI will be brought to the notice of the chairperson of the IEC in writing.

Surprisingly, with regard to voting power, only in five SOPs, was it mentioned that a member with $\mathrm{COI}$ will not have the right to vote on a decision. An earlier study (16) recorded a mixed observation: in some IEC meetings, members who had declared $\mathrm{COI}$ were requested to leave the IEC meeting room at the time of decision-making; while in other IEC meetings, members with Col were allowed to sit in the room but were debarred from voting. This shows that those who were entrusted with drafting the SOPs were either untrained or poorly motivated, and did not refer to the standard guidelines while drafting the SOPs.

We observed that the majority of the IECs had used consensus of the board as the decision-making method, while in one IEC, the decision was based on majority vote. Our findings were at par with the ICMR 2017 guidelines (1: p 42).

\section{Record keeping and archiving}

In our study, the majority of SOPs mentioned how long they would keep or archive the documents related to IEC reviews. However, the duration of record keeping varied from a minimum of 5 years to a maximum of 15 years. Poor archiving and record keeping are the areas of concern connected to the functioning of IECs (18). The ICMR 2017 guidelines reiterate that all documents and communication of IECs need to be dated, filed, and preserved as per written procedures. Archiving of records must be for a period of 3 years after the termination of the study. However, documents related to regulatory clinical trials must be archived for 5 years or as per regulations (1: $p$ 46).

\section{Administration and budget}

It was found that seven out of the nine SOPs of the IECs had a provision for designated office space and staff and for allocation of budget. A survey of public sector teaching hospitals in Delhi conducted by Singh S, in 2009, noted that adequate administrative support was present in $71 \%$ of the IECs, while inadequate financial support or absence of financial support was recorded in $43 \%$ of IECs (10).Other studies conducted earlier showed that the effectiveness of research ethics committees in many countries is greatly restricted by the lack of resources (20). ICMR 2017 guidelines (1: $p$ 47) state that all the IECs should have their own office space, independent staff and budget.

Therefore, it may be mentioned that, in the NE region, there is still scope to strengthen the administrative and management capacity of IECs by providing adequate infrastructure, ensuring dedicated time for members, and keeping provision for a budget.

\section{Registration and accreditation of IECS}

To our surprise, we found that most of the IECs of the NE region were not registered under CDSCO and not accredited. Therefore, they were not eligible to conduct any regulatory trial. As per Gol, Drugs and Cosmetics Rules, 1945, no ethics 
committee shall review and accord its approval to a clinical trial protocol without prior registration with the licensing authority as defined in clause (b) of rule 21 (2). It is mandatory to renew the registration of IECs every three years to remain eligible to carry out clinical trials. However, very few had renewed their registration. This reflects the poor state of IECs currently available in the NE region. Also, regulatory trials are rarely being conducted.

\section{Conclusions}

Our findings show that the characteristics and composition of many existing IECs of biomedical and health research institutes in NE India are below par and not registered with the registering authority. The majority of the SOPs are not framed with reference to the ICMR 2017 guidelines. Therefore, it may be concluded that the mechanisms for ethical reviewing of research proposals involving human participants are weak and cause for major ethical concern.

\section{Limitations of our study}

The study was limited to only $\mathrm{MCl}$-recognised medical colleges of the NE Region and two of the Government of India health research institutes in Assam. The IECs of private sector institutions were not part of this study. There was no $\mathrm{MCl}-$ recognised Medical College in Nagaland and Mizoram at the time of our study. Therefore, these findings cannot be generalised to all IECs of this region. Moreover, two of the institutes had not constituted their IECs, and three of the IECs had not framed their SOPs. As such, it is not appropriate to comment on the profile of the IECs and the status of SOPs of these institutes.

\section{Conflicts of interests and funding: None declared.}

\section{Acknowledgements}

The authors would like to thank Dr Vasantha Muthuswamy, Former Senior Deputy DG, ICMR and President, Forum for Ethics Review Committees in India (FERCI), who helped in the initial stages of the study design for carrying out this study.

\section{References}

1. Indian Council of Medical Research. National Ethical Guidelines for Biomedical and Health Research Involving Human Participants. New Delhi: ICMR; 2017 [cited 2020 Jul 8]. Available from: https://icmr.nic.in/ sites/default/files/guidelines/ICMR_Ethical_Guidelines_2017.pdf

2. Ministry of Health and Family Welfare, Government of India. The Drugs and Cosmetics Act, 1940 and Rules 1945. [cited 2020 Nov 7]. Available from https://cdsco.gov.in/opencms/export/sites/CDSCO_WEB/Pdfdocuments/acts_rules/ 2016DrugsandCosmeticsAct1940Rules1945.pdf
3. Perryer S. Medical research is conducted in developing countries to avoid ethics legislation. New Economy. 2019 Jun 10 [cited 2020 Nov 7]. Available from: https://www.theneweconomy.com/strategy/medicalresearch-is-conducted-in-developing-countries-to-avoid-ethicslegislation

4. Board of Governors in Supersession of the Medical Council of India. Minimum Qualifications for Teachers in Medical Institutions (Amendment) Regulations, 2019. The Gazette of India: Extraordinary. New Delhi: BoG; 2020 Feb 12 [cited 2020 Jul 9]. Available from: https:// mciindia.org/ActivitiWebClient/open/getDocument?path=/ Documents/Public/Portal/Gazette/TEQ-17.02.2019.pdf

5. Nair YM, Martin DK. Concerns about ethical review of health research in India. Indian J Med Ethics. 2004 Oct-Dec; 1(4):119-20.

6. Ahmad K. Developing countries need effective ethics review committees. Lancet. 2003 Aug 23;362(9384):627.

7. Kumar NK. Bioethics activities in India. East Mediterr Health Jl. 2006; 12 (Supp.1) ,S56-65[cited 2020 November 7]. Available from: https:// apps.who.int/iris/handle/10665/117186

8. Schedule Y. Requirements and guidelines for permission to import and/ or manufacture of new drugs for sale or to undertake clinical trials. 2014 May 8[cited 2020 April 7] Available from: https://rgcb.res.in/ documents/Schedule-Y.pdf

9. Kadam R, Karandikar S. Ethics committees in India: Facing the challenges. Perspect Clin Res. 2012 Apr-Jun; 3(2): 50-6.

10. Singh S. Procedures and operations of Institutional Ethics Committees. Indian J Med Res. 2009 Nov; 130(5):568-9.

11. Kirigia JM, Wambebe $C$, Baba-Moussa A. Status of national research bioethics committees in the WHO African region. BMC Med Ethics. 2005;6:10. Available from: https://doi.org/10.1186/1472-6939-6-10

12. Sleem $\mathrm{H}, \mathrm{El}$-Kamary $\mathrm{S}$, Silverman $\mathrm{H}$. Identifying structures, processes, resources and needs of research ethics committees in Egypt.BMC Medical Ethics. 2010 Jun; 11(1):12.Doi: 10.1186/1472-6939-11-12.

13. Zielinski C, Kebede D, Mbondji PE, Sanou I, Kouvividila W, Lusamba -Dikassa P-S. Research ethics policies and practices in health research institutions in sub-Saharan African countries: results of a questionnaire-based survey. J R Soc Med. 2014 Mar; 107(1S): 70-6.

14. National Institute of Malaria Research. Standard Operating Procedures of Institutional Ethics Committee. Version 1.2010 Apr 6 [cited 2020 Nov 7]. Available from: http://back.nimr.org.in/assets/ sop.pdf

15. Moodley K, Myer L. Health Research Ethics Committees in South Africa 12 years into democracy. BMC Medical Ethics. 2007 Jan; 8:1. [cited 2020 Nov 7]. Available from: http://www.biomedcentral.com/14726939/8/1

16. Panichkul S, Mahaisavariya P, Morakote N, Condo S, Caengow S, Ketunpanya A. Current status of the research ethics committees in Thailand. J Med Assoc Thai. 2011 Aug 1; 94(8):1013-8

17. Saito T. Ethics committees in Japanese medical schools. HEC Forum 1992; 4(4):281-7. Doi:10.1007/BF00057793.

18. Thatte UM, Bavdekar SB. Clinical research in India: Great expectation? J Postgrad Med. 2008 Oct-Dec; 54(4):318-23.

19. Brahme R, Mehendale S. Profile and role of the members of ethics committees in hospitals and research organisations in Pune, India. Indian J Med Ethics. 2009 Apr-Jun; 6(2): 78-84. Doi: 10.20529/IJME. 2009.026.

20. Dickens BM, Cook RJ: Challenges of ethical research in resource-poor settings. Int J Gynaecol Obstet. 2003 Jan; 80(1):79-86. Doi: 10.1016/ s0020-7292(02)00349-1. 